\title{
Truncated apo B-70.5-containing lipoproteins bind to megalin but not the LDL receptor
}

\author{
Zhouji Chen, ${ }^{1}$ Jeffrey E. Saffitz, ${ }^{2}$ Mickey A. Latour, ${ }^{1}$ and Gustav Schonfeld ${ }^{1}$
}

${ }^{1}$ Division of Atherosclerosis, Lipid Research and Nutrition, Department of Medicine, and

${ }^{2}$ Department of Pathology, Washington University School of Medicine, St. Louis, Missouri 63110, USA

Address correspondence to: Zhouji Chen, Division of Atherosclerosis, Lipid Research and Nutrition, Department of Medicine, Washington University School of Medicine, Box 8046, 660 S. Euclid Avenue, St. Louis, Missouri 63110, USA. Phone: (314) 747-4352; Fax: (314) 362-3513; E-mail: zchen@imgate.wustl.edu.

Received for publication August 14, 1998, and accepted in revised form April 16, 1999.

Apo B-100 of LDL can bind to both the LDL receptor and megalin, but the molecular interactions of apo B-100 with these 2 receptors are not completely understood. Naturally occurring mutant forms of apo B may be a source of valuable information on these interactions. Apo B-70.5 is uniquely useful because it contains the $\mathrm{NH}_{2}$-terminal portion of apo B-100, that includes only one of the two putative LDL receptor-binding sites (site A). The lipoprotein containing apo B-70.5 (Lp B-70.5) was purified from apo B100/apo B-70.5 heterozygotes by sequential ultracentrifugation combined with immunoaffinity chromatography. Cell culture experiments, ligand blot analysis, and in vivo studies all consistently showed that Lp B-70.5 is not recognized by the LDL receptor. The kidney was identified as a major organ in catabolism of Lp B-70.5 in New Zealand white rabbits. Autoradiographic analysis revealed that renal proximal tubular cells selectively removed Lp B-70.5. On ligand blotting of renal cortical membranes, Lp B-70.5 bound only to megalin. The ability of megalin to mediate cellular endocytosis of Lp B-70.5 was confirmed using retinoic acid/dibutyryl cAMP-treated F9 cells. This study suggests that the putative LDL receptor-binding site A on apo B-100 might not by itself be a functional binding domain and that the apo B-binding sites recognized by the LDL receptor and by megalin may be different. Moreover, megalin may play an important role in renal catabolism of apo B truncations, including apo B-70.5.

J. Clin. Invest. 103:1419-1430 (1999).

\section{Introduction}

Catabolism of apo B-containing lipoproteins primarily depends on a receptor-mediated process, especially via the LDL receptor-mediated pathway, which plays a pivotal role in determining plasma cholesterol homeostasis in humans and other species (1). Apo B-100 is the major protein component of LDL and is the ligand responsible for the receptor-mediated cellular uptake and catabolism of LDL (1,2). Although the structural and functional domains of the LDL receptor have been defined in detail (3), the exact receptor-binding site on apo B-100 is yet to be completely elucidated. Apo B is a very large protein with highly hydrophobic and lipophilic domains (4), and it is difficult to study its structure-function relationships. Nevertheless, based on the information about the primary structure $(5,6)$ and phylogenetic and immunochemical studies (7-10) localizing the receptor-binding domain, 2 basic amino acid sequences in the $\mathrm{COOH}$-terminal region of apo B-100, i.e., residues 3120-3156 (site A) and residues 3352-3371 (site B), have been proposed as putative LDL receptor-binding sites $(4,9)$. However, the exact role of these 2 regions in mediating the interaction between LDL and its receptor remains to be established.

Truncated apo B-containing lipoproteins, resulting from mutations producing premature stop codons in the apo $\mathrm{B}$ gene in patients with the genetic disorder familial hypobetalipoproteinemia (11), have proved to be useful in further defining the molecular interaction of apo B-100 with its receptor. Krul et al. (12) have shown that truncation of the COOH-terminal $25 \%$ of apo B-100 does not impair the ability of the truncated apo B to bind to the LDL receptor. On the other hand, Young et al. (13) and Welty et al. (14) showed that $\mathrm{NH}_{2}$-terminal $37 \%$, or even $67 \%$, of apo B-100 does not contain an LDL receptor-binding domain, thereby providing strong evidence in support of the notion that the functional LDL receptor-binding domain for apo B-100 is located within a region between apoB-67 and apo B-75, namely, amino acids 3040-3387. Nevertheless, these studies could not produce further information regarding the relative role of the 2 putative receptor-binding sites of apo B-100 in mediating its interaction with the LDL receptor, because the apo B truncations used contain neither or both of the putative binding sites.

Apo B-70.5, which was previously identified by us from a hypobetalipoproteinemic kindred (15), terminates at amino acid residue 3196, and thus, it contains only site A and not site B of the 2 putative LDL receptor-binding sites on apo B-100. Furthermore, the subjects with apo B-70.5 were homozygous for apo E-2 (15), an apo E isoform that is defective for LDL receptor binding (16), thus enabling us unequivocally to distinguish between the binding activities of apo B and apo E. Therefore, lipoprotein particles containing apo B-70.5 (Lp B-70.5) from these subjects could provide us unique opportunities to examine the role of putative binding site A in mediating the binding of apo B-100 to the LDL receptor.

In addition to its ability to bind to the LDL receptor, apo B-100 is capable of binding to megalin/glycoprotein 330 (17), a member of the LDL receptor family $(18,19)$. 
However, the fact that this receptor is apparently expressed only in extravascular tissues (19), especially in the renal proximal tubule epithelial cells $(19,20)$, raises questions as to how it could play a role in mediating clearance of LDL from the blood circulation. Interestingly, we have recently identified the kidney as a major organ in catabolism of short apo B truncations (21). It is not known whether the kidney also plays a role in catabolism of the longer forms of apo B truncations and whether megalin is involved in the renal uptake of truncated apo B-containing lipoproteins.

In the present study, we demonstrated that Lp B-70.5 does not bind to the LDL receptor but is capable of binding to megalin and that the kidney also plays an important role in catabolism of this apo B truncation. These findings suggest that putative LDL receptor-binding site A might not by itself be a functional binding domain. Furthermore, megalin, which may be responsible for mediating renal uptake of truncated apo B, recognizes a different binding domain(s) on the apo B-100 than that recognized by the LDL receptor.

\section{Methods}

Anti-apo B mAb's 234 and 4G3 were kindly provided by Y.L. Marcel (University of Ottawa, Ottawa, Ontario, Canada). Anti-apo A-I mAb's were previously developed by us. Cyanogen bromide-activated Sepharose-4B, glutathione-agarose, BSA, and thrombin were purchased from Sigma Chemical Co. (St. Louis, Missouri, USA). $\mathrm{Na}^{125} \mathrm{I}$ and $\mathrm{Na}^{131} \mathrm{I}$ (carrier-free in aqueous solution; pH 8-10) were obtained from Amersham Life Sciences Inc. (Arlington Heights, Illinois, USA). The plasmid-containing glutathione-S-transferase-receptor-associated protein (GST-RAP) fusion protein gene (22) was a kind gift from J. Herz (University of Texas, Dallas, Texas, USA). Dilactitol tyramine (DLT) was

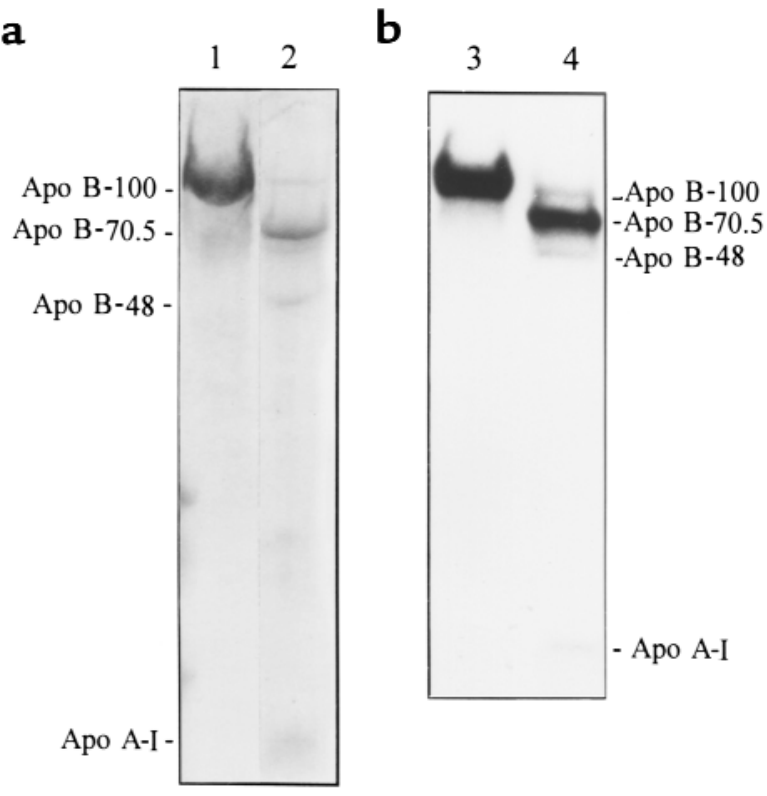

\section{Figure 1}

Coomassie staining (a) and autoradiographic analysis (b) of control LDL and purified Lp B-70.5 separated on 3-12\% SDS-PAGE. Lane 1, $15 \mu \mathrm{g}$ control LDL; lane 2, $5 \mu \mathrm{g}$ Lp B-70.5; lane 3, $0.5 \mu \mathrm{g}{ }^{125} \mathrm{I}-\mathrm{LDL}$; and lane 4, $0.5 \mu \mathrm{g}^{125} \mathrm{I}$-Lp B-70.5. kindly provided by S.R. Thorpe (University of South Carolina, Columbia, South Carolina, USA). All other chemicals used were of analytical grade and obtained from commercial sources.

Human subjects and blood collection. The apo B-70.5 kindred was originally described by us (15). This mutation was caused by an adenine (A) insertion into a 7-A repeat between nucleotides 9754 and 9760 of the apo $\mathrm{B} c \mathrm{CNA}$, leading to premature termination of translation at amino acid residue 3196 of the apo B-100 (15). The 2 apo B-70.5/B-100 heterozygotes are apo E-2 homozygotes by genotyping (15). One hundred milliliters of fasted blood was obtained from the heterozygotes. Blood was also obtained from unrelated normolipidemic subjects. The blood was drawn into tubes containing EDTA $(1 \mathrm{mg} / \mathrm{mL})$, and plasma was separated by centrifugation. Aprotinin $(100 \mathrm{KIU} / \mathrm{mL})$ and an antioxidant, butylated hydroxytoluene $(300 \mu \mathrm{M})$, were added to the plasma.

Isolation and characterization of $L p$ B-70.5. Lp B-70.5 particles were isolated by ultracentrifugation combined with anti-apo B-100 and anti-apo A-I immunoaffinity chromatography. Initial experiments were carried out to test the ability of a panel of $\mathrm{COOH}$ terminal-specific anti-apo B mAb's to bind to apo B 100-containing lipoprotein particles by immunoprecipitation. Of 4 antibodies tested, $\mathrm{mAb} 234$, which recognizes an epitope located within the region between apo B-89 and apo B-100, was found to bind to both LDL and VLDL with high affinities. Therefore, this antibody was used for subsequent experiments. To generate immunoaffinity columns, $15 \mathrm{mg}$ of $\mathrm{mAb} 234$ and $10 \mathrm{mg}$ of a mixture of 3 anti-apo A-I mAb's were covalently bound to $3 \mathrm{~g}$ (12 $\mathrm{mL})$ and $2 \mathrm{~g}(8 \mathrm{~mL})$ of cyanogen bromide-activated Sepharose$4 \mathrm{~B}$, respectively, according to manufacturer's instruction.

Lipoproteins in the density range of $1.022-1.085 \mathrm{~g} / \mathrm{mL}$ were isolated from Lp B-70.5-containing plasma by sequential ultracentrifugation after adjusting the plasma density with potassium bromide (23). This density range was chosen because we previously showed that most of the Lp B-70.5 particles were distributed in these densities (15). After extensive dialysis in column buffer $(50 \mathrm{mM}$ Tris- $\mathrm{HCl}[\mathrm{pH} 7.5]$ containing $0.9 \% \mathrm{NaCl}$ and $0.01 \%$ EDTA), the lipoprotein preparation was incubated with $10 \mathrm{~mL}$ of $\mathrm{mAb} 234$-coupled column at $8-10^{\circ} \mathrm{C}$ for 3 hours. Lp B-70.5 and other unbound proteins were eluted from the column with $60 \mathrm{~mL}$ of column buffer. The flow-throughs were pooled and concentrated to $6 \mathrm{~mL}$ using Centriprep-50 (Millipore Corp., Bedford, Massachusetts, USA) and then incubated in the anti-apo A-I mAb-coupled column at $8-10^{\circ} \mathrm{C}$ for 2 hours. Unbound proteins (i.e., Lp B-70.5) were eluted from the column with $40 \mathrm{~mL}$ of column buffer. The Lp B-70.5-containing solutions were pooled, adjusted to a density of 1.080 $\mathrm{g} / \mathrm{mL}$ with $\mathrm{KBr}$, and ultracentrifuged for 18 hours (23) to remove the remaining serum albumin and apo A-I contaminants and to recover the Lp B-70.5. The columns were regenerated by eluting the bound proteins (i.e., apo B-100 LDL) with 3 M KSN solution ( $\mathrm{pH} 7.0$ ). Control apo B-100 LDL was isolated from plasma of the normal subjects by sequential ultracentrifugation (23) and processed through a sham column in which no antibody was coupled. The purified lipoproteins were analyzed both by Coomassie blue staining after SDS-PAGE (3-12\%) of the unlabeled lipoproteins and by autoradiographic analysis of the ${ }^{125}$ I-labeled lipoproteins.

Radiolabeling of proteins. Iodination of control LDL or Lp B70.5 was carried out by the modified MacFarlane iodine monochloride method (24). The labeled lipoproteins were sterilized by filtering through $0.45-\mu \mathrm{m}$ Millipore filters, stored at $4^{\circ} \mathrm{C}$, and used within a week. Radioiodinated DLT was prepared and conjugated to Lp B-70.5 or control LDL as described $(25,26)$ and used within 24 hours. The GST-RAP fusion protein and purified megalin were radioiodinated using an IODO-GEN iodination reagent (Pierce Chemical Co., Rockford, Illinois, USA). The radioactivity in all radiolabeled products was at least 95\% precipitable with trichloroacetic acid (TCA). 
Plasma clearance kinetics and organ distributions of labeled lipoproteins in rabbits. The residualizing label-conjugated lipoproteins, ${ }^{125}$ I-DLT-Lp B-70.5 and ${ }^{131}$ I-DLT-control LDL ( $1 \mathrm{~mL}$ in sterilized saline), were simultaneously injected into $3 \mathrm{New}$ Zealand white (NZW) rabbits (female, $1.4 \mathrm{~kg}$ ) via the marginal ear veins. Blood samples were taken at 5, 10, 30, 60, 120, 240, 480, 720, and 1,440 minutes after injection. TCA-precipitable counts (more than $95 \%$ of the total) were determined and used for calculations of the fractional catabolic rates (FCR) using the twocompartment SAAM model (27).

For determination of radioactivity in tissues, the rabbits were anesthetized with sodium pentobarbital 24 hours after injection, and their bodies were perfused with saline containing 5 $\mathrm{U} / \mathrm{mL}$ heparin, as described (21). After perfusion, the animals were sacrificed with overdoses of sodium pentobarbital. Tissues were weighed, and samples were taken for determination of radioactivity. Masses of dispersed organs (adipose, skeletal muscle, digestive tube, and skin) were estimated from their percentage of the total body mass (28).

Autoradiographic analysis of uptake of Lp B-70.5 by the kidney. To determine the cell type responsible for the renal catabolism of Lp B-70.5, ${ }^{125}$ I-DLT-Lp B-70.5 or ${ }^{125}$ I-DLT-control LDL $(~ 150 \mu \mathrm{g}$ protein for each label containing $7-8 \mu \mathrm{Ci}^{125}$ I-radioactivity) was injected into different NZW rabbits. Blood samples were taken and FCRs were estimated as already described here. At 24 hours after injection, tissue distributions of the radioactivity were also determined. Blocks of the kidney ( $2 \mathrm{~mm}$ in thickness), including both cortical and medullary tissues, were obtained and immediately fixed in $10 \%$ buffered formaldehyde solution for 24 hours. Sections $(10 \mu \mathrm{m})$ were prepared from paraffin blocks of the fixed kidney, mounted on gelatin-coated slides. After removing the paraffin with xylene and rehydrating the tissues, the slides were dipped in Kodak Nuclear Tract Emulsion, type NTB2 (Eastman Kodak Co., Rochester, New York, USA) diluted at 1:1 with distilled water. After exposure for 5 weeks, the slides were developed, stained with hematoxylin and eosin, and examined by light microscopy.

Ligand blot analysis. Renal cortical membranes were purified and solubilized as described by Moestrup et al. (29), and solubilized bovine adrenal gland membranes were prepared according to Schneider et al. (30). To perform the ligand blot analysis, $200 \mu \mathrm{g}$ of the solubilized membrane proteins was separated on $3-12 \%$ SDS-PAGE under nonreducing conditions and transferred onto Immobilon-P membranes (Millipore Corp.). The membranes were blocked by incubating in binding buffer $(20$ $\mathrm{mM}$ Tris- $\mathrm{HCl}$ [pH 7.5], $150 \mathrm{mM} \mathrm{NaCl}, 2 \mathrm{mM} \mathrm{CaCl}_{2}$, and $1 \mathrm{mM}$ $\mathrm{MgCl}_{2}$ ) containing $2 \%$ nonfat dried milk for 2 hours at room temperature. The membrane strips were then incubated at room temperature for 2 hours in $4 \mathrm{~mL}$ of binding buffer/1\% BSA containing ${ }^{125} \mathrm{I}-\mathrm{LDL}(1 \mu \mathrm{g} / \mathrm{mL}),{ }^{125} \mathrm{I}-\mathrm{RAP}-\mathrm{GST}(0.2 \mu \mathrm{g} / \mathrm{mL})$, or ${ }^{125} \mathrm{I}-\mathrm{Lp}$ B-70.5 $(1 \mu \mathrm{g} / \mathrm{mL})$ with or without the specified competitors. After this incubation, the strips were washed with icecold binding buffer 4 times for 5 minutes each and were then air dried and exposed to Kodak x-ray films for 10 hours.

Purification of megalin and solid phase-binding assay. Megalin was purified from rabbit kidney cortical membranes according to the procedure of Moestrup et al. (29) using a 15-mL RAP affinity column. The RAP affinity column was prepared by coupling $25 \mathrm{mg}(15 \mathrm{~mL})$ of GST-RAP fusion protein to $4 \mathrm{~g}(14 \mathrm{~mL})$ of cyanogen-bromide-activated Sepharose-4B. Approximately 1.5 $\mathrm{mg}$ of protein was purified from $1.8 \mathrm{~g}$ of membrane proteins after applying the purification procedure to the same membrane preparation twice. The purity of the purified receptor was examined by SDS-PAGE. To obtain partial amino acid sequence of the purified protein, $25 \mu \mathrm{g}$ protein was subjected to trypsin digestion, followed by reverse-phase HPLC purification of the protein digest. Three fragments of the tryptic digest were sequenced on a Perkin-Elmer Applied Biosystem (Procite model 494; Foster City, California, USA) using standard reagents.

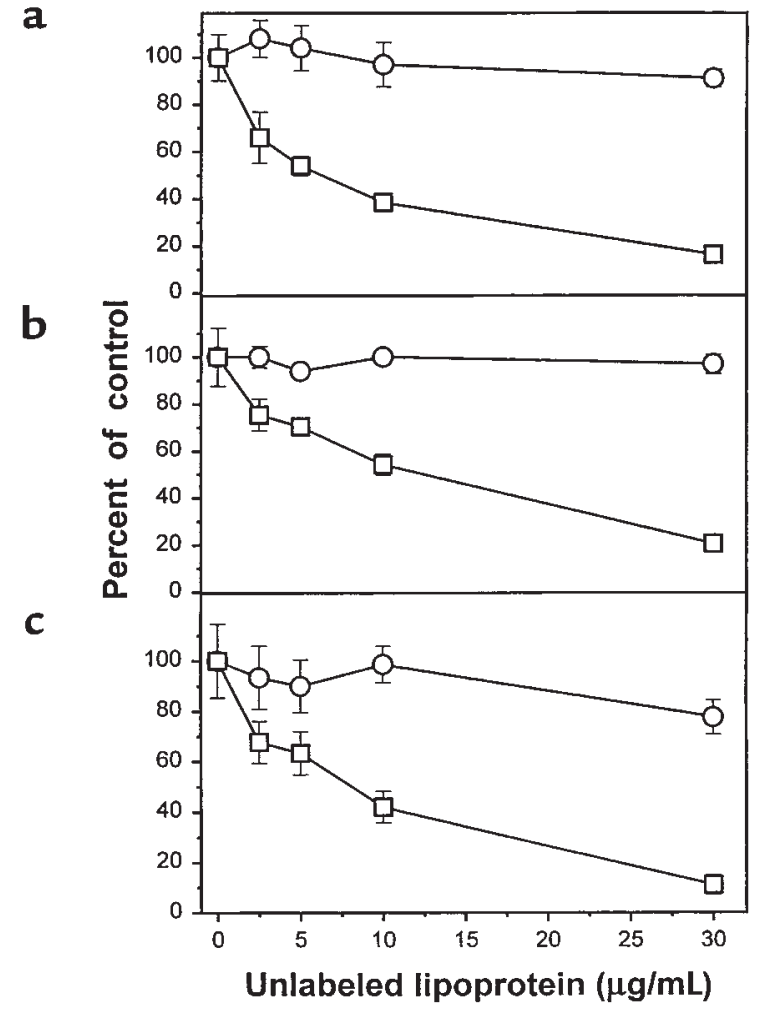

Figure 2

Ability of unlabeled Lp B-70.5 and control LDL (apo B-100 LDL) to compete with ${ }^{125}$ I-labeled apo B-100 LDL for the LDL receptor-mediated binding (a), internalization (b), and degradation (c) by TR-715 cells. The cell monolayers were cultured in Ham's F-12 containing 10\% lipoprotein-deficient FBS for 48 hours, followed by incubation in MEM/0.5\% BSA containing $1 \mu \mathrm{g}{ }^{125} \mathrm{I}-\mathrm{LDL} / \mathrm{mL}$ alone or with the indicated amounts of unlabeled Lp B-70.5 (open circles) or apo B-100 LDL (open squares) at $37^{\circ} \mathrm{C}$ for 4 hours Thereafter, the amounts of ${ }^{125}$-LDL bound, internalized, or degraded were determined. Values obtained from incubations in the presence of $100 \mu \mathrm{g}$ unlabeled control $\mathrm{LDL} / \mathrm{mL}$ were considered nonspecific values and subtracted from the totals. Each data point represents the mean \pm SD $(n=3)$.

To perform solid phase-binding assays, Maxisorb microtiter wells (Nunc A/S, Roskilde, Denmark) were coated with megalin, BSA, or Lp B-70.5 $(5 \mu \mathrm{g} / \mathrm{mL}$ coating concentration $)$ at $37^{\circ} \mathrm{C}$ for 4 hours. After blocking with $2 \%$ BSA in binding buffer ( $20 \mathrm{mM}$ Tris$\mathrm{HCl}$ [pH 7.5], $150 \mathrm{mM} \mathrm{NaCl}$, and $2 \mathrm{mM} \mathrm{CaCl}_{2}$ ), the wells were rinsed with binding buffer $/ 1 \%$ BSA 3 times, followed by incubation with ${ }^{125}$ I-labeled Lp B-70.5 or ${ }^{125}$ I-labeled megalin alone or with the specified competitors in $100 \mu \mathrm{L}$ of binding buffer $/ 1 \%$ BSA for 4 hours at $25^{\circ} \mathrm{C}$. After this incubation, wells were washed with ice-cold binding buffer 5 times $(300 \mu \mathrm{L}$ each), and the bound labeled ligands were removed by incubating in $200 \mu \mathrm{L}$ of $0.5 \mathrm{~N}$ $\mathrm{NaOH}$ solution and counted for ${ }^{125} \mathrm{I}$ radioactivity.

To demonstrate further the interaction of apo B with megalin, thrombin-treated apo B-100 LDL and untreated LDL were electrophoresed on SDS-PAGE (3-6\% gradient gel) under reducing conditions and transferred onto Immobilon- $P$ membranes, followed by incubation with ${ }^{125} \mathrm{I}$-megalin $(2 \mu \mathrm{g} / \mathrm{mL})$ according to the procedure used for ligand blot analysis already described here. Thrombin digestion of LDL was carried out at $15^{\circ} \mathrm{C}$ for 16 hours in $300 \mu \mathrm{L}$ of Tris-buffered saline $(10 \mathrm{mM}$ Tris- $\mathrm{HCl}$; $\mathrm{pH}$ 8.0) at an enzyme/apo B-100 protein ratio of 1:50 (wt/wt).

Cell culture studies. TR-715 cells, a line of Chinese hamster ovary cells that were stably transfected with human LDL receptor cDNA (31), kindly provided by M.S. Brown and J.L. Goldstein (University of Texas, Dallas, Texas, USA), were maintained 


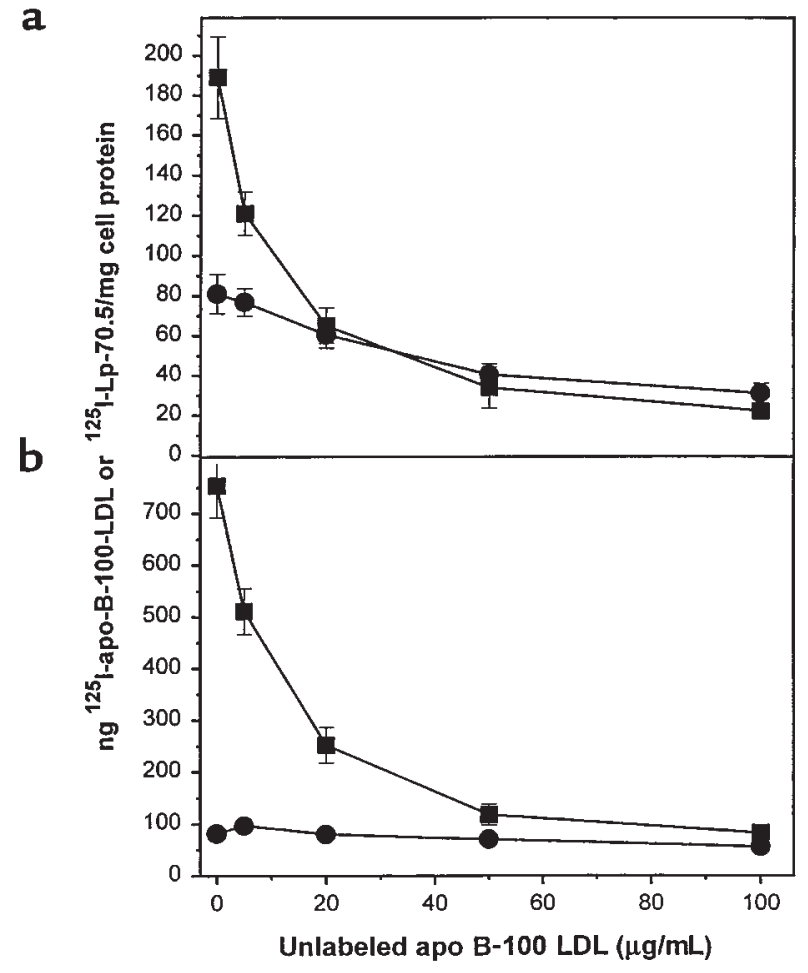

Figure 3

Uptake and degradation of ${ }^{125}$ I-Lp B-70.5 and ${ }^{125}$ I-apo B-100 LDL by TR715 cells. The cell monolayers were cultured in Ham's F-12 containing $10 \%$ lipoprotein-deficient FBS for 48 hours, followed by incubation in MEM $/ 0.5 \%$ BSA containing fixed amounts $(1 \mu \mathrm{g} / \mathrm{mL})$ of ${ }^{125} \mathrm{l}$-apo B-100 LDL (filled squares) or ${ }^{125} \mathrm{I}$-Lp B-70.5 (filled circles) alone or with the indicated amounts of unlabeled apo B- $100 \mathrm{LDL}$ at $37^{\circ} \mathrm{C}$ for 4 hours. Thereafter, the plates were placed on ice to stop the reactions. After standard wash, amounts of cell-associated labeled lipoproteins (a) were determined. TCA-soluble organic ${ }^{125}$-radioactivity in the medium was determined to measure degradation of the labeled lipoproteins (b). Wells containing no cells were treated in the same manner, and the resulting values were subtracted from the corresponding total values. Each data point represents the mean $\pm \mathrm{SD}(n=3)$.

in Ham's F-12 /FBS (10\%). To perform cell studies, cells were seeded into 12-well culture plates (Corning Glass Works, Corning, New York, USA) at a concentration of $0.5 \times 10^{5}$ cells per well and cultured in complete medium for 3 days. Thereafter, the medium was replaced with lipoprotein-deficient FBS $(10 \%) / H a m$ 's F-12 medium, and cells were cultured for 2 additional days. After this incubation, cell monolayers were washed with MEM $/ 0.5 \% \mathrm{BSA}$ and then incubated at $37^{\circ} \mathrm{C}$ for 4 hours in $1 \mathrm{~mL} \mathrm{MEM} / 0.5 \%$ BSA medium containing ${ }^{125} \mathrm{I}$-apo B-100 LDL or ${ }^{125} \mathrm{I}-\mathrm{Lp}$ B-70.5 at $1 \mu \mathrm{g} / \mathrm{mL}$ with or without the specified competitors. At the end of this incubation, plates were placed onto ice for 10 minutes. To determine degradation of the labeled lipoproteins, aliquots $(500 \mu \mathrm{L})$ of medium were transferred into tubes $(12 \mathrm{~mm} \times 75 \mathrm{~mm})$, followed by additions of $100 \mu \mathrm{L}$ of $2 \% \mathrm{BSA}$ and $600 \mu \mathrm{L}$ of ice-cold $20 \%$ TCA solution. The tubes were vortexed, incubated on ice for 1 hour, and centrifuged to pellet the TCA precipitates. Organic ${ }^{125}$ I radioactivity of the resultant supernatants was counted after removing inorganic ${ }^{125} \mathrm{I}$ with $5 \% \mathrm{AgNO}_{3}$ solution as described (32). For the measurement of ligand binding and internalization, cells were washed twice with ice-cold PBS $/ 0.2 \%$ BSA solution followed by 3 washes with ice-cold PBS (standard wash). After the final wash, cells were incubated at $4^{\circ} \mathrm{C}$ for 1 hour with 10 $\mathrm{mg} / \mathrm{mL}$ dextran sulfate in PBS $(1 \mathrm{~mL}$ per well) to dissociate the cell surface-bound ligands (33). The medium was removed and counted for radioactivity to determine cell surface-bound ligands, whereas the cells were dissolved with $0.1 \mathrm{~N} \mathrm{NaOH}$ and counted for internalized ligands.

Mouse F9 embryonic teratocarcinoma cells (F9 cell) (CRL1720; American Type Culture Collection, Rockville, Maryland, USA) were maintained in DMEM/10\% FBS medium on plates coated with $0.1 \%$ gelatin. This cell line was chosen for the experiments to examine the ability of megalin to mediate uptake and degradation of Lp B-70.5 because its expression of megalin, but not the LDL receptor or the LDL receptor-related protein, can be dramatically stimulated upon differentiation induced by treatment with retinoic acid (RA) and cAMP $(17,34)$. Furthermore, megalin-mediated endocytosis of apo B-100 LDL has been well documented in the RA/cAMP-treated F9 cells (17). To induce differentiation, subconfluent cultures were incubated in DMEM $/ 15 \%$ FBS medium containing RA $(0.2 \mu \mathrm{M})$ and dibutyryl cAMP ( $\left.\mathrm{Bt}_{2} \mathrm{cAMP}\right)(1 \mathrm{mM})$ for 7 days. To perform ligand uptake and degradation assays, untreated or $\mathrm{RA} / \mathrm{Bt}_{2} \mathrm{CAMP}$-treated cells were seeded into 12 -well gelatincoated plates $\left(0.4 \times 10^{6}\right.$ cells per well $)$ and cultured in DMEM/10\% FBS medium for 18 hours. Thereafter, cells were washed with $2 \mathrm{~mL}$ of serum-free DMEM/0.5\% BSA and then incubated at $37^{\circ} \mathrm{C}$ for 4 hours in DMEM $/ 0.5 \%$ BSA containing the specified radiolabeled lipoproteins $(2 \mathrm{nM})$ with or without competitors. After the incubation, TCA-soluble organic ${ }^{125} \mathrm{I}$ radioactivity in the medium was determined as already described here for TR-715 cells to estimate the degradation of the labeled lipoproteins, and cell-associated ${ }^{125}$ I-labeled lipoproteins were determined after standard wash.

The OK cells (passage 90-95), an opossum renal proximal tubule cell line, were kindly provided by K. Martin (St. Louis University, St. Louis, Missouri, USA) and maintained in $\mathrm{MEM} / 10 \% \mathrm{FBS}$. To differentiate these cells fully, they were cultured for 5 days after reaching confluence $(35,36)$. To examine the ability of these cells to take up and degrade the specified ligands, they were plated onto 12 -well dish $\left(0.4 \times 10^{6}\right.$ cells per well $)$ and cultured in MEM/10\% FBS medium for 1 day. OK cell monolayers were then washed with MEM/0.5\% BSA and incubated for 4 hours at $37^{\circ} \mathrm{C}$ in MEM/0.5\% BSA containing the specified labeled ligands $(2 \mathrm{nM})$ with or without competitors. After this incubation, cells and medium were processed as already described here for F9 cells.

All of the assays described here were carried out in triplicate incubations. Radioactivities from the sham incubations of wells containing no cells were considered background values (less than $5 \%$ of the total) and subtracted from the corresponding values. Miscellaneous procedures. GST and GST-RAP fusion protein were generated and purified as described (22). Protein contents of the samples were determined with a modified Lowry method (37). Cholesterol, esterified cholesterol, phospholipid, and triglyceride contents of the lipoproteins were determined using diagnostic kits (Wako Pure Chemicals Industries, Osaka, Japan). Data were presented as the mean \pm SD of the number of determinations.

\section{Results}

Isolation and characterization of the Lp B-70.5 particles. Lp B70.5 particles are present in plasma of our subjects mainly in the density range of $1.022-1.085 \mathrm{~g} / \mathrm{mL}$ (15). Based on Western blot analysis, the concentrations of apo B70.5 in these subjects are $15 \%$ of those of apo B-100. We purified Lp B-70.5 by selectively removing apo B-100 and apo A-I from lipoproteins in this density range using COOH-terminal-specific anti-apo B-100 and anti-apo A-I immunoaffinity columns. Initial experiments indicated that the anti-apo B mAb used in this procedure 
(i.e., $\mathrm{mAb} 234$ ) recognizes an epitope that is located within the COOH-terminal $11 \%$ of the apo B-100 and expressed on most of the apo B-100-containing lipoprotein particles (data not shown). Thus, the mAb 234-coupled column enabled us completely to remove the apo B100 particles from the lipoprotein preparation. After immunoaffinity chromatography, the Lp B-70.5 preparations were subjected to further ultracentrifugation at a density of $1.080 \mathrm{~g} / \mathrm{mL}$ to remove the remaining trace amounts of albumin, apo A-I contaminants, and the aggregated lipoprotein particles, if any, formed during the purification process. In fact, more than $90 \%$ of the proteins were recovered from this re-ultracentrifugation step. Using this procedure, we were able to isolate $\sim 400$ $\mu \mathrm{g}$ protein of Lp B-70.5 from $40 \mathrm{~mL}$ plasma. That most of the Lp B-70.5 particles floated at the proper density indicates that they were physically intact. The purity of the final Lp B-70.5 preparation was examined by SDSPAGE analysis and Coomassie blue staining and by autoradiography of the ${ }^{125} \mathrm{I}$-labeled LP B-70.5. Both methods showed that the purified Lp B-70.5 was nearly devoid of apo B-100, with only trace amounts of apo B48 and apo A-I remaining (Figure 1, a and b). Occasionally, there appeared to be a faint protein band on the gel with a migration position close to the apo E molecular size, but Western blot analysis detected no apo E on these LP B-70.5 particles (data not shown). We have previously shown that the Lp B-70.5 particles are smaller than those of apo B-100 LDL and partially overlap with the HDL particle sizes $(11,15)$. We confirmed this observation by sizing the ${ }^{125} \mathrm{I}-\mathrm{Lp}$ B-70.5, ${ }^{125} \mathrm{I}$-apo B-100 LDL, and ${ }^{125} \mathrm{I}-$ HDL using a fast-performance liquid chromatography (FPLC) column (data not shown). The Lp B-70.5 particles contained slightly less core lipids (i.e., triglycerides and cholesterol esters) and more surface lipid components (i.e., free cholesterol and phospholipids) than the apo B-100 LDL from the apo B-70.5/B-100 heterozy-
Table 1

Chemical compositions of apo B-containing lipoproteins isolated from apo B-70.5/apo B-100 heterozygotes

\begin{tabular}{lrrrrr}
\hline \multicolumn{7}{c}{ Percent of total } \\
& Protein & TG & CE & FC & PL \\
& 9.87 & 52.82 & 10.39 & 6.85 & 18.56 \\
VLDL/IDLA & 28.94 & 4.96 & 13.2 & 17.32 & 35.82 \\
Lp B-70.5 & 36.48 & 5.15 & 24.89 & 11.59 & 21.89 \\
LDL-B-100 $^{\text {B }}$ & 37.82 & 7.14 & 21.85 & 9.66 & 23.53 \\
Control LDLC & 3.9 & & & \\
\hline
\end{tabular}

ALipoproteins from the apo B-100/apo B-70.5 heterozygotes isolated at density of 1.019. ${ }^{B}$ The fraction of LDL isolated from the apo B-100/apo B-70.5 heterozygotes that was bound to the mAb 234-coupled column. ${ }^{2} \mathrm{LDL}$ isolated from the plasma of control subjects. CE, cholesterol esters; FC, free cholesterol; PL, phospholipids; TG, triglycerides.

gotes or from the control subjects (Table 1), whereas chemical compositions of the apo B-100 LDL particles isolated from heterozygote plasma were similar to those of control apo B-100 LDL (Table 1).

Inability of $L p B-70.5$ to interact with buman $L D L$ receptor expressed on TR-715 cells. To examine the ability of LP B70.5 to interact with the LDL receptor pathway, we first tested whether they are capable of competing with ${ }^{125} \mathrm{I}$ labeled control apo B-100 LDL for metabolism by TR715 cells, a line of human LDL receptor cDNA transfectants (31). As shown in Figure 2, Lp B-70.5 did not compete with ${ }^{125} \mathrm{I}$-apo B-100 LDL for binding, internalization, or degradation, even at the highest concentration used, whereas control LDL competed effectively, indicating that Lp B-70.5 may not interact with the LDL receptor. To confirm this observation further, Lp B-70.5 was radiolabeled with ${ }^{125} \mathrm{I}$, and direct uptake and degradation of the labeled Lp B-70.5 by TR-715 cells were compared with those of ${ }^{125}$ I-LDL B-100. Under identical conditions, these cells metabolized at least 10 times more ${ }^{125}$ I-LDL B-100 than ${ }^{125}$ I-Lp B-70.5 (Figure 3), and

\section{Figure 4}

Organ distribution of the recovered ${ }^{125} \mathrm{I}$ - or ${ }^{131} \mathrm{I}$-radioactivity in NZW rabbits 24 hours after injection of ${ }^{131}$ I-DLT-apo B-100 LDL and ${ }^{125}$ I-DLT-Lp B-70.5 (a) and the relative uptake activity of selected organs (b). In a, the values are presented as mean \pm SD of $(n=3)$. In $\mathbf{b},{ }^{125}$ | and ${ }^{131}$ | radioactivities accumulated in the indicated organs of the rabbits were expressed as disintegrations per minute per gram of wet tissue and normalized by the values from the liver. The values are presented as mean $\pm \operatorname{SD}(n=3)$. a

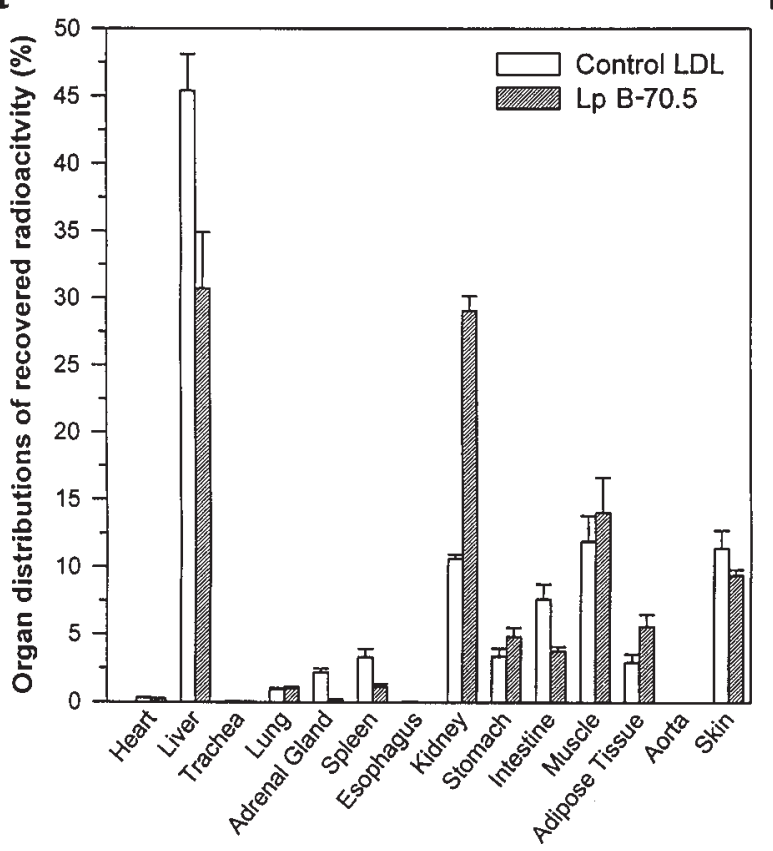

b

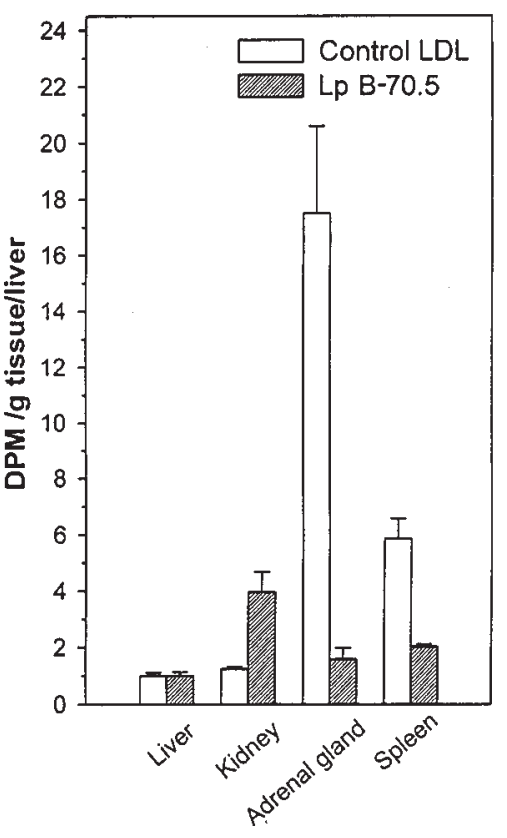


125I-DLT-Lp B-70.5
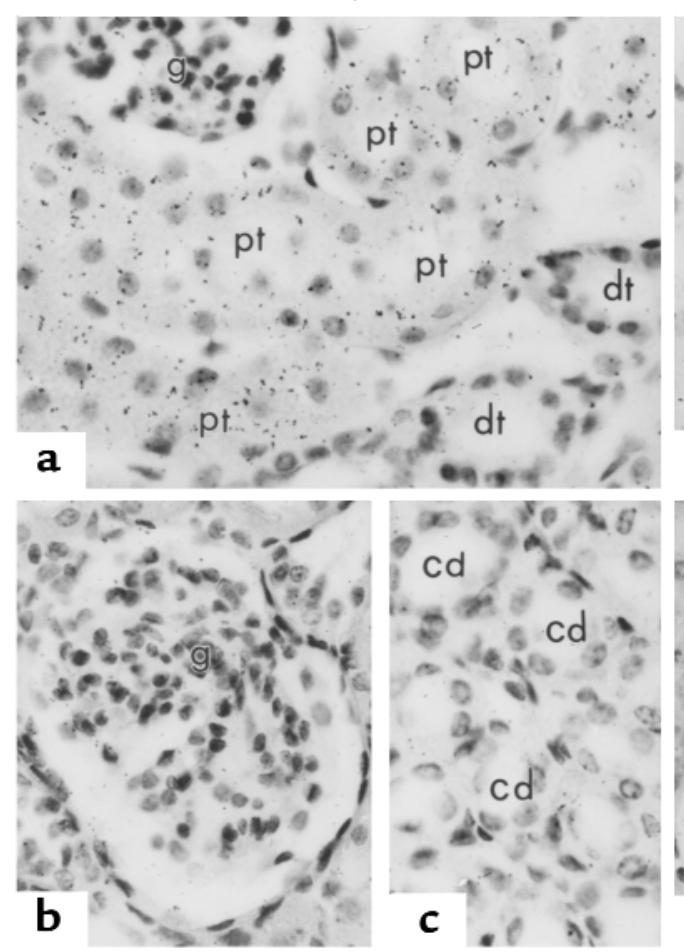
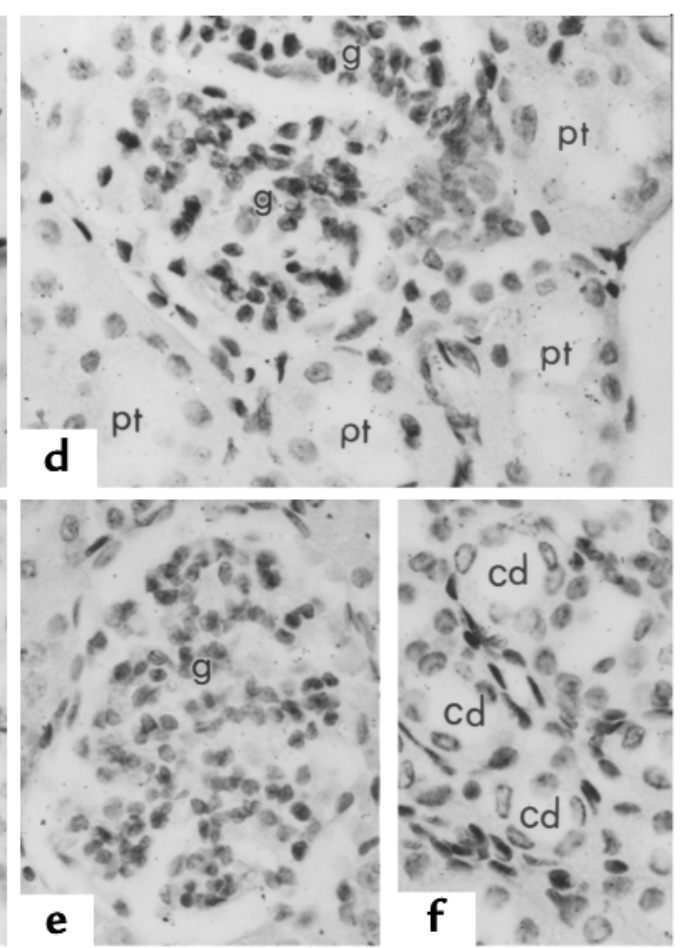

Figure 5

Autoradiograms of renal tissues from rabbits 24 hours after injection of $8 \mu \mathrm{Ci}$ of ${ }^{125}$ I-DLT-Lp B-70.5 or ${ }^{125}$ I-DLT-apo B-100 LDL. Organ distributions of ${ }^{125}$-radioactivity in these rabbits were similar to those described in Figure 4 . Tissue sections were prepared for autoradiography as described in Methods. ( $\mathbf{a}$ and $\mathbf{d})$ Renal cortex, $\times 400$. ( $\mathbf{b}$ and $\mathbf{e})$ Glomerulus, $\times 600$. ( $\mathbf{c}$ and $\mathbf{f}$ ) Renal medulla, $\times 400$. cd, collecting duct; dt, distal tubule; g, glomerulus; pt, proximal tubule. Note that silver grains are mainly localized to the proximal tubular cells of the ${ }^{125}$ I-DLT-Lp B-70.5-injected rabbit (a).

apo B-100 LDL did not compete with ${ }^{125}$ I-Lp B-70.5 for cellular degradation.

Organ loci and renal cellular localization of catabolism of $L p B$ 70.5 in rabbits. As the first step to explore the possible cellular mechanism responsible for catabolism of LP B-70.5, we performed in vivo experiments to determine organ loci of catabolism of Lp B-70.5. When simultaneously injected into NZW rabbits, ${ }^{125}$ I-DLT-Lp B-70.5 was cleared at nearly twice the rate of ${ }^{131}$ I-DLT-apo B-100 LDL (FCR: 0.098/h for Lp B-70.5 vs. 0.057/h for LDL). At 24 hours after injection, about $75 \%$ of the initial ${ }^{125}$ I-Lp B-70.5 and $55 \%$ of ${ }^{131}$ IDLT LDL had been cleared from the circulation.

The kidney and liver played equally important roles in the uptake and catabolism of Lp B-70.5, with each organ accounting for $30-35 \%$ of the whole-body uptake (Fig- ure 4a). In contrast, the liver was the predominant organ in apo B-100 LDL uptake (Figure 4a). The kidney uptake of apo B-100 LDL accounted for $10 \%$ of the whole-body uptake, which is only $20 \%$ of the liver uptake (Figure 4a). The adrenal gland had a high uptake of apo B-100 LDL per unit weight of tissue and a negligible uptake of Lp B70.5 , whereas the kidney showed the highest uptake activity per unit weight of tissue for Lp B-70.5 (Figure $4 \mathrm{~b})$. These results were consistent with our previous study on short truncations of apo B (21) and demonstrated that the kidney is a major organ for catabolism of truncated apo B-containing lipoproteins.

To determine cellular localization of uptake activity for Lp B-70.5 in the kidney, autoradiographic analysis was performed on kidney sections from ${ }^{125}$ I-DLT-LP B-

\section{Figure 6}

Ligand blots demonstrating the ability of Lp B-70.5 to bind to megalin from rabbit kidney cortical membrane extracts. Approximately $200 \mu \mathrm{g}$ of proteins of solubilized membranes from rabbit kidney cortex $(\mathrm{K})$ or adrenal gland $(\mathrm{A})$ of the cow was subjected to SDS-PAGE (3-12\% gradient gel) under nonreducing conditions and transferred onto Immobilon- $\mathrm{P}$ membranes. Ligand blot was performed as described in Methods. Membrane strips 1, 2, and 3 were incubated with the indicated labeled ligands $(1 \mu \mathrm{g} / \mathrm{mL})$ alone, whereas strips 4-8 were incubated with ${ }^{125} \mathrm{I}$-Lp B-70.5 $(1 \mu \mathrm{g} / \mathrm{mL})$ in the absence or presence of the indicated unlabeled inhibitors (i.e., $10 \mathrm{mM}$ EDTA, $100 \mu \mathrm{g} / \mathrm{mL}$ LDL, $30 \mu \mathrm{g} / \mathrm{mL}$ GST-RAP, or $15 \mu \mathrm{g} / \mathrm{mL}$ GST). The exposure time of the films was 3 hours for strip 2 and 10 hours for all other strips.
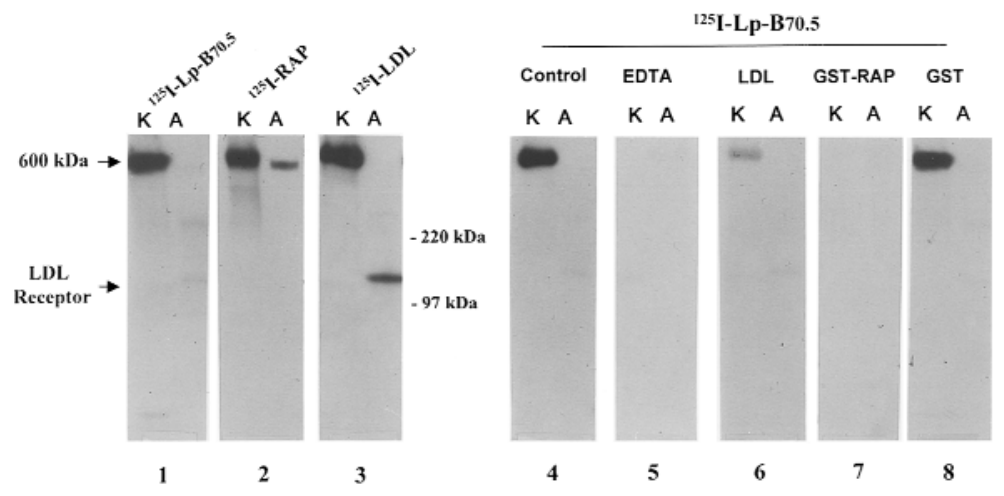


\section{Figure 7}

Coomassie staining of the purified rabbit megalin (a) and its binding to ${ }^{125}$ I-Lp B-70.5 on ligand blot (b). (a) Rabbit kidney cortical membrane $(r K M)$ protein $(300 \mu \mathrm{g})$ or the purified rabbit megalin (Meg; $4 \mu \mathrm{g}$ ) was separated on SDS-PAGE (3-12\% gradient gel) under nonreducing conditions and subjected to Coomassie staining. (b) Ligand blot analysis was performed as described in Figure 6 . hKM, $250 \mu \mathrm{g}$ of human kidney cortical membranes; Meg., $2 \mu \mathrm{g}$ of the purified rabbit megalin; rKM, $200 \mu \mathrm{g}$ of rabbit kidney cortical membranes. 125I-Lp B-70.5 was present in the binding solution at a concentration of $1 \mu \mathrm{g} / \mathrm{mL}$.

70.5- or ${ }^{125}$ I-DLT-apo B-100 LDL-injected NZW rabbits. ${ }^{125}$ I radioactivity was predominantly accumulated in the proximal tubule cells of the ${ }^{125} \mathrm{I}$-DLT-Lp B70.5-injected rabbits (Figure 5a), whereas much lower activities were observed in the glomerulus (Figure 5b) and none were seen in the distal tubule cells or collecting ducts (Figure 5c). These data indicated that proximal tubule cells were mainly responsible for the renal catabolism of Lp B-70.5. As expected, little uptake was seen in the kidney sections of ${ }^{125}$ I-DLT-apo B-100 LDL-injected rabbits (Figure 6, d-f).

Ability of Lp B-70.5 to bind to megalin from renal cortical membranes. Megalin is abundant in renal proximal tubule cells $(19,20)$ and is capable of binding to apo B100 (17). Identification of the renal proximal tubule cell as the major cell type responsible for renal uptake of $\mathrm{LP}$ $\mathrm{B}-70.5$ raises the possibility that this receptor might mediate the catabolism of Lp B-70.5 in the kidney. To test this possibility, ligand blot analysis was performed on rabbit renal cortical membrane proteins. Bovine adrenal gland membrane proteins were included in the assay as a positive control for the LDL receptor and a negative control for megalin. Lp B-70.5, apo B-100 LDL, and RAP, which is a well-characterized ligand for megalin $(17,19)$, all bound to a single protein band from renal cortical membranes with a molecular weight of $\sim 600 \mathrm{kDa}$ (Fig-
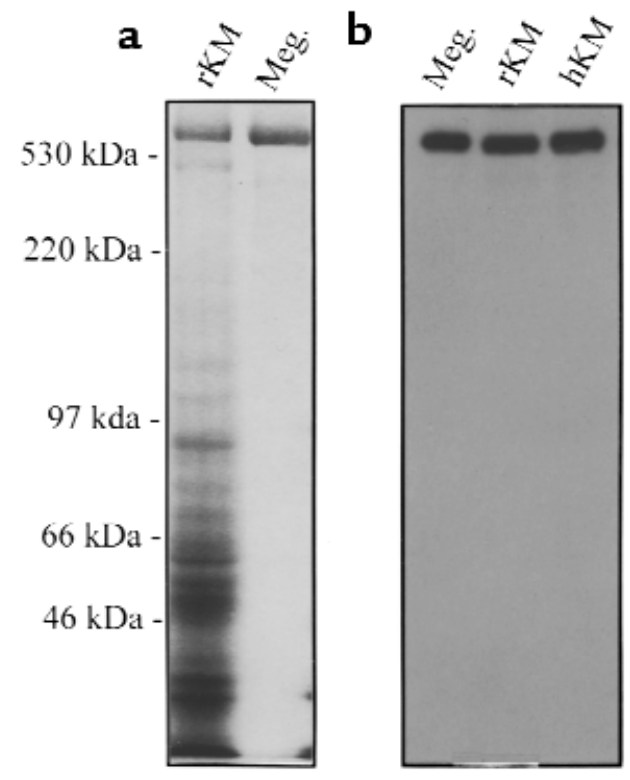

ure 6), which corresponds to the size of megalin $(19,29)$. No megalin band was seen on the adrenal gland membranes, but there was a slightly smaller protein band corresponding to the LDL receptor-related protein $(\sim 500$ $\mathrm{kDa})$ seen on membrane strip incubated with ${ }^{125}$ I-RAP (Figure 6). The binding of Lp B-70.5 to the putative megalin band could be inhibited by EDTA, excess LDL, or GST-RAP (Figure 6). As expected, LDL bound to the LDL receptor band from the bovine adrenal gland membranes, whereas little binding to the LDL receptor was seen for Lp B-70.5 (Figure 6). Taken together, these results suggest the ability of Lp B-70.5 to bind to megalin and further document the lack of interactions between Lp B-70.5 and the LDL receptor.
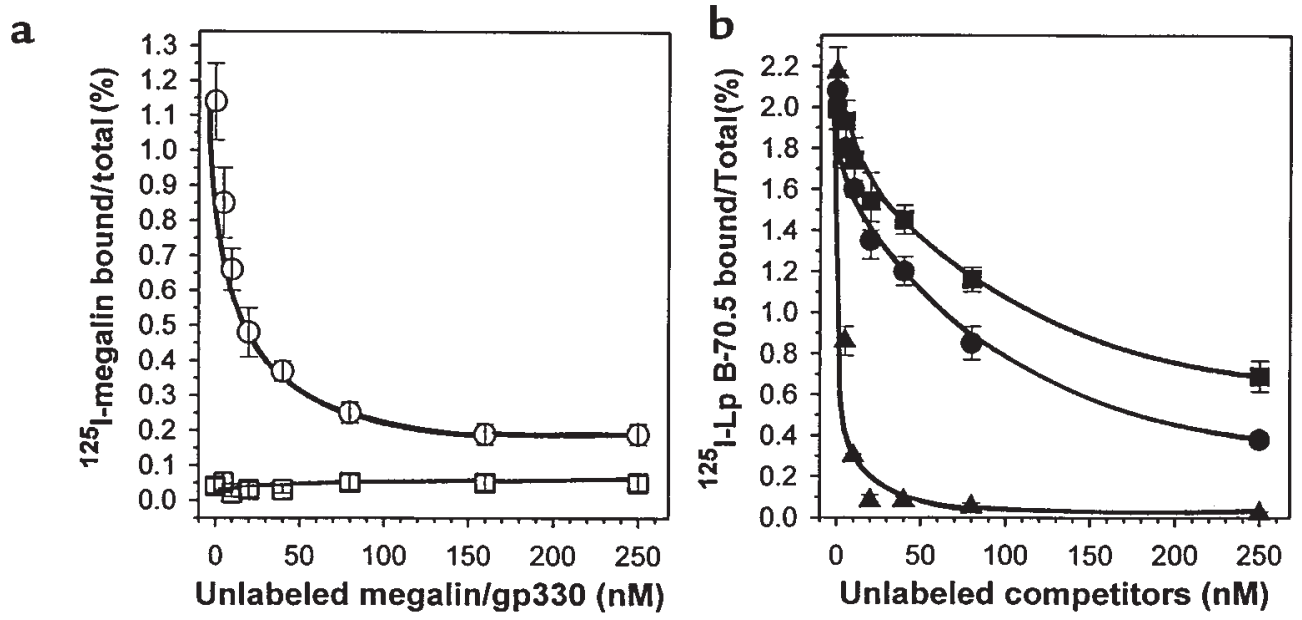

\section{Figure 8}

Interactions between Lp B-70.5 and rabbit megalin demonstrated by solid phase-binding assays. Rabbit megalin was purified and solid phase-binding assays were performed as described in Methods. (a) Binding of ${ }^{125}$-megalin $(2 \mathrm{nM}$ ) to microtiter wells coated with Lp B-70.5 (open circles) or BSA (open squares) in the presence of increasing concentrations of unlabeled megalin. (b) Binding of ${ }^{125} \mathrm{I}-\mathrm{Lp}$ B-70.5 ( $2 \mathrm{nM}$ ) to microtiter wells coated with megalin in the presence of increasing concentrations of unlabeled Lp B-70.5 (filled circles), control LDL (filled squares), or RAP (filled triangles). Nonspecific binding was determined on BSA-coated microtiter wells (less than $8 \%$ of the total) and subtracted from the total binding counts. Each data point represents the mean \pm SD $(n=3)$. 


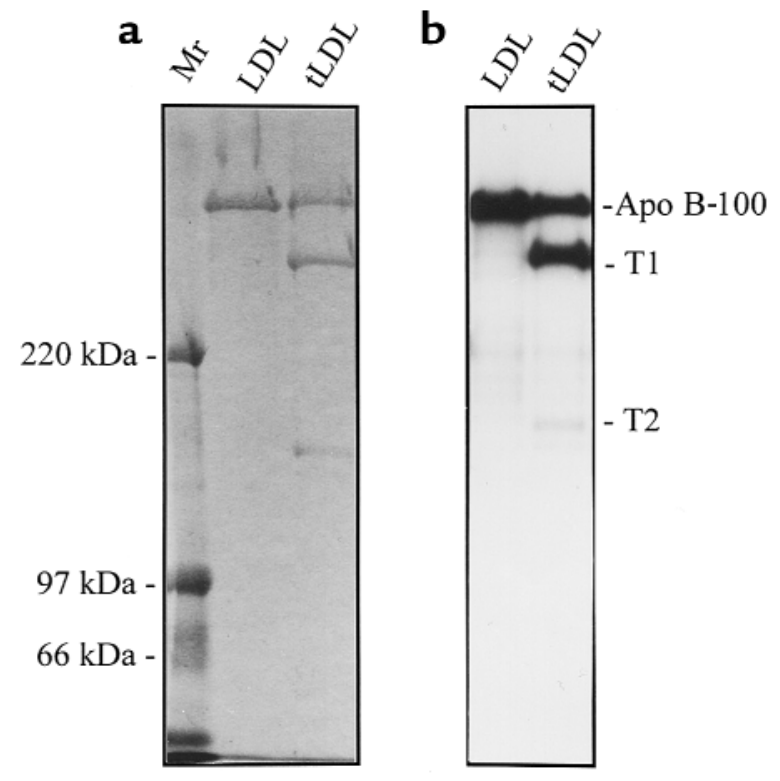

\section{Figure 9}

Binding of ${ }^{125}$-megalin to immobilized thrombin-cleavage fragments of apo B-100. Thrombin-treated LDL (tLDL) was prepared by incubating $\mathrm{LDL}$ with thrombin at $15^{\circ} \mathrm{C}$ for 16 hours. Untreated LDL (LDL) and tLDL were electrophoresed on 3-6\% SDS-PAGE under reducing conditions. (a) Coomassie blue staining of LDL $(5 \mu \mathrm{g})$ or tLDL $(5 \mu \mathrm{g})$. (b) Binding of 125 megalin ( $2 \mu \mathrm{g} / \mathrm{mL}$ in ligand blot binding buffer) to LDL $(2 \mu \mathrm{g})$ or tLDL (2 $\mu \mathrm{g})$ after electrophoresis and transfer onto Immobilon-P membranes. The binding assay was performed using the ligand blot procedure described in Methods.

To ascertain the ability of Lp B-70.5 to interact with megalin, we purified this receptor from rabbit kidney cortical membranes. The purity of the purified protein is shown by Figure 7a. The identity of this protein as megalin was verified by protein sequencing, in which the $\mathrm{NH}_{2}$-terminal sequences of $12-15$ amino acids obtained from 3 trypsin-digested fragments of the purified protein share more than $95 \%$ identities with 3 regions on rat (18) and human (38) megalin (data not shown). As shown by Figure 7b, ${ }^{125} \mathrm{I}-\mathrm{Lp}$ B-70.5 bound to the purified megalin on ligand blot. In addition, a similar protein band was identified from human kidney membranes (Figure $7 \mathrm{~b}$ ), indicating the ability of human megalin to recognize Lp B-70.5. The interaction between Lp B-70.5 and megalin was also demonstrated by solid phase-binding assays. ${ }^{125} \mathrm{I}$-megalin bound to Lp B-70.5-coated microtiter wells but not to BSA-coated wells (Figure 8a). Conversely, ${ }^{125}$ I-LP B-70.5 specifically bound to microtiter wells coated with megalin (Figure 8b). This binding could be inhibited by increasing doses of unlabeled apo B-100 LDL and RAP as well as unlabeled Lp B70.5 (Figure $8 \mathrm{~b})$. The derived dissociation constant $\left(K_{\mathrm{d}}\right)$ for the binding of Lp B-70.5 to the purified rabbit megalin was $\sim 35 \mathrm{nM}$, which is slightly lower than the $K_{\mathrm{d}}(50$ $\mathrm{nM})$ for normal LDL reported by Stefansson et al. (17).

The ability of Lp B-70.5 to interact with megalin, despite its inability to interact with the LDL receptor, suggests that the LDL receptor and megalin might recognize different domains on apo B-100. To test this possibility, we examined the ability of megalin to bind to the apo B-
100 fragments generated by thrombin digestion. As shown by Figure 9, megalin bound to apo B-100 and the $\mathrm{NH}_{2}$-terminal fragment of the thrombin-cleaved product (the T1 fragment but not the remaining $\mathrm{COOH}$-terminal portion of apo B-100, i.e., the T2 fragment). The identities of the designated bands as T1 and T2 fragments were verified by immunoblot analysis using the $\mathrm{NH}_{2}$-terminal-specific anti-apo B mAb C1.4 (10) and the COOHterminal-specific antibody mAb 234 (data not shown).

Uptake and degradation of Lp B-70.5 by F9 cells and OK cells. To demonstrate that the interaction of Lp B-70.5 with megalin leads to endocytosis of the lipoprotein particle, we examined the uptake and degradation of Lp B-70.5 by F9 cells that were treated with $\mathrm{RA} / \mathrm{Bt}_{2} \mathrm{CAMP}$ to induce megalin expression $(17,34)$. The induced expression of megalin in the treated cells was confirmed by ligand blot analysis using ${ }^{125}$ I-GST-RAP (data not shown). Although little Lp B-70.5 or control apo B-100 LDL was metabolized by untreated F9 cells (Figure 10, a and c), both were taken up and degraded avidly by the differentiated cells (Figure 10, b and d). Treated F9 cells increased the uptake and degradation of Lp B-70.5 by 3-and 6-fold, respectively, whereas the uptake and degradation of control LDL were increased only by 2 - and 3 -fold, respectively. The greater degree of degradation of Lp B-70.5 in treated F9 cells is the reverse of what occurred in TR-715 cells, in which uptake and degradation of apo B-100 LDL were much higher than that of Lp B-70.5 (Figure 3), suggesting that megalin mediates cellular catabolism of LP B-70.5. Similar to the ligand blots, uptake and degradation of Lp B-70.5 by differentiated F9 cells were effectively inhibited by LDL and GST-RAP (Figure 10, $\mathrm{b}$ and d), further indicating that Lp B-70.5 was metabolized in these cells via the megalin-mediated pathway.

We also examined the renal proximal tubule OK cells for their ability to metabolize Lp B-70.5. Because megalin expression had not, to our knowledge, been documented previously in this cell line, we first tested the ability of these cells to metabolize GST-RAP. GST-RAP was taken up and degraded actively by these cells in a highaffinity, specific receptor-mediated manner (data not shown). Furthermore, ligand blot analysis of OK cell membranes using ${ }^{125}$ I-GST-RAP as a ligand identified a single protein band corresponding to the megalin band (data not shown). Both Lp B-70.5 and control apo B-100 LDL were avidly taken up and degraded by OK cells in a manner similar to the RA/Bt ${ }_{2}$ CAMP-treated F9 cells, i.e., inhibitable with unlabeled GST-RAP and LDL (Figure 11), further supporting the possible role of megalin in mediating the renal uptake and catabolism of Lp B-70.5.

\section{Discussion}

Naturally occurring truncated apo B-containing lipoproteins are useful in studying the structure-function relationships of apo B-100, especially in understanding the molecular interactions between LDL and its receptors (12-14). In this context, apo B-70.5 is of unique usefulness because it contains the $\mathrm{NH}_{2}$-terminal portion of apo B100 that includes only 1 of the 2 putative LDL receptor-binding sites, namely, site A. We have used Lp B-70.5 isolated from plasma of the apo B-70.5/B-100 subjects to address the following issues: (a) the role of putative LDL 
receptor-binding site $\mathrm{A}$ in mediating the interaction between apo B-100 and the LDL receptor; (b) the organ loci and cellular localization of catabolism of Lp B-70.5 in vivo; and (c) the ability of apo B-70.5 to interact with megalin. Our results demonstrate that apo B-70.5 does not bind to the LDL receptor, suggesting that putative binding site $\mathrm{A}$ alone is not sufficient for mediating the apo B-100 LDL receptor interaction. However, the apo B-70.5 truncation does retain its ability to bind to megalin, indicating that distinct regions on apo B-100 might be involved in its interactions with LDL receptor and megalin. In addition, our results suggest that Lp B-70.5 is directed to the kidney for catabolism, probably through the megalin-mediated pathway.

The inability of apo B-70.5 to interact with the LDL receptor pathway was manifested by data obtained both from in vitro experiments and from in vivo studies. First, by using cells that were stably transfected with the human LDL receptor cDNA, TR-715 cells (31), we demonstrated that LP B-70.5 were unable to compete with ${ }^{125} \mathrm{I}$-apo B-100 LDL for binding to the LDL receptor. The lack of binding of Lp B-70.5 to the LDL receptor was further demonstrated by ligand blot analysis. Consistent with these results, we found that the uptake and degradation of ${ }^{125}$ I-Lp B-70.5 by TR-715 cells were much less than those of ${ }^{125} \mathrm{I}$-apo B-100 LDL. Second, our in vivo study showed that the adrenal gland took up little Lp B-70.5, whereas it avidly utilized the concurrently injected apo B-100 LDL. As the adrenal gland is known to express a large number of LDL receptors to recruit plasma LDL-carried cholesterol for steroidogenesis (39), this finding provides physiological evidence supporting our conclusion that apo B-70.5 does not interact with the LDL receptor. Taken together, these results indicate that putative binding site A alone may not be recognized by the LDL receptor. Previous studies on other apo B truncations (12-14) have localized the LDL receptor-binding site to the region between apo B-67 and apo B-75 (i.e., residues 3040-3387). Combined with these studies, our study provides evidence suggesting that the region spanning residues 3196-3387 functions as a binding domain by itself or in combination with other sites such as site A. It could be argued that the binding site A region might not be folded properly on the Lp B-70.5 particles and thus is not accessible to the receptor. However, Lp B70.5 was immunoprecipitated by mAb 4G3 (data not shown), which recognizes an epitope on apo B-100 of the LDL particles that is about 30 residues upstream of the putative binding site A (9), suggesting that the conformation of the region encompassing binding site $\mathrm{A}$ on apo B-70.5 may be similar to that of apo B-100 LDL.

That the putative binding site A of apo B-100 does not bind to the LDL receptor in the absence of site $\mathrm{B}$ is also supported by other studies. For example, the LDL receptor-binding site on apo $\mathrm{E}$ has been well defined because of its being smaller than that of apo B-100 and because of the existence of a large number of natural mutations in apo $\mathrm{E}$ that disrupt the binding $(40,41)$. It was found

\section{Figure 10}

Uptake and degradation of ${ }^{125}$-apo B-100 LDL and $125 \mathrm{I}-\mathrm{LP}$ B-70.5 by untreated and $\mathrm{RA} / \mathrm{Bt}_{2} \mathrm{CAMP}$-treated $\mathrm{F9}$ cells. Low levels of cell association (a) and degradation (c) of ${ }^{125}$ I-apo B-100 LDL or ${ }^{125}$-Lp B-70.5 in untreated F9 cells. Increased levels of cell association (b) and degradation (d) of ${ }^{125}$ I-apo B-100 LDL or ${ }^{125}$ Lp B-70.5 in treated F9 cells. Inhibitions of cellular association and degradation of ${ }^{125}$-LDL or 125I-Lp B-70.5 by unlabeled LDL or GST-RAP are also shown. The amounts of cell-associated and degraded ${ }^{125}$-labeled ligands were determined as described in Methods. Wells containing no cells were treated in the same manner, and the resulting values were subtracted from the corresponding total values. Each data point represents the mean $\pm \operatorname{SD}(n=3)$.
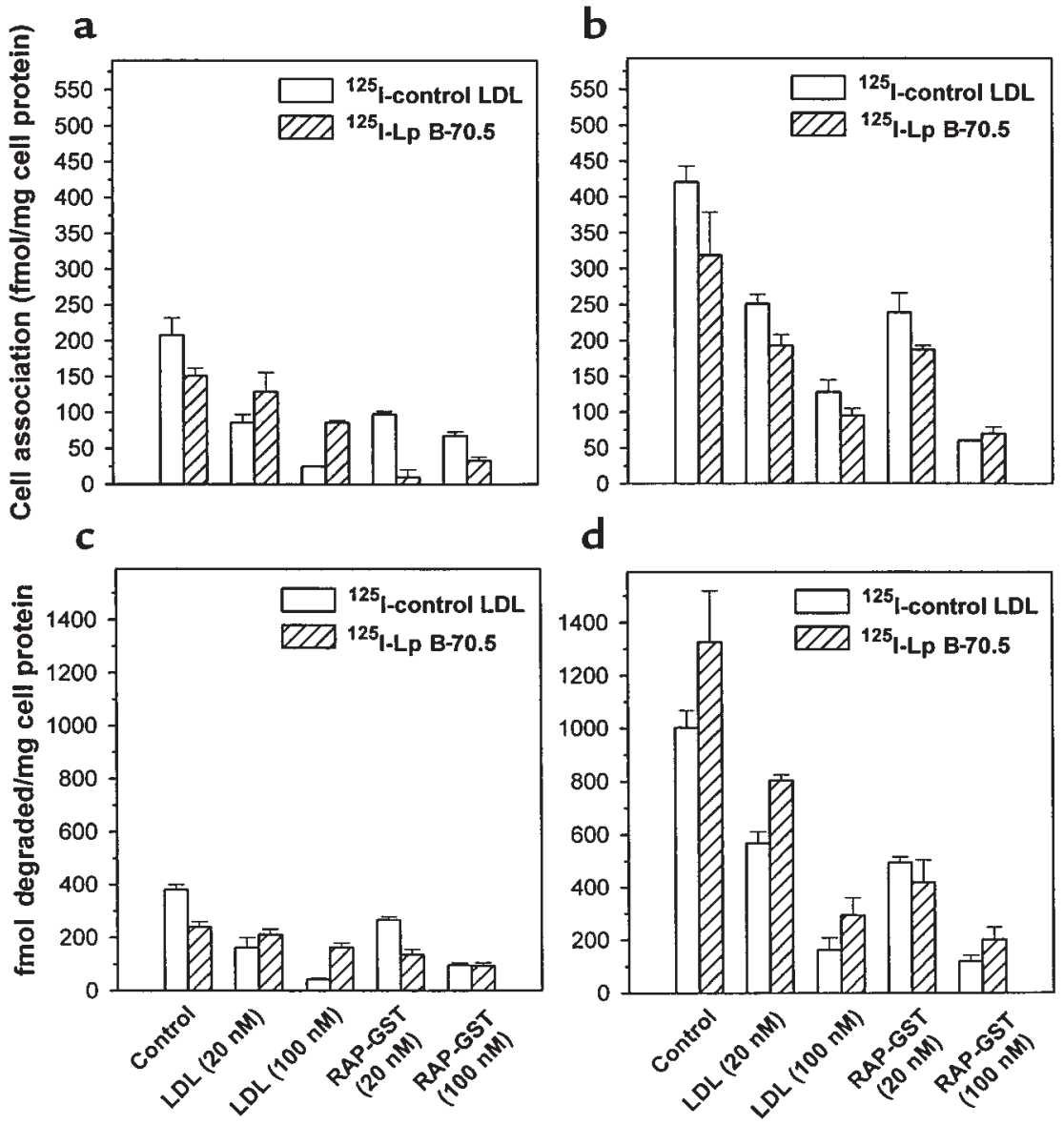


\section{Figure 11}

${ }^{125}$-apo B-100 LDL and ${ }^{125}$ I-Lp B-70.5 were metabolized to a similar extent by OK cells. The amounts of specifically cell-associated (a) or degraded (b) ${ }^{125}$ I-apo B LDL and ${ }^{125}$ I-Lp B-70.5 were determined as described in Methods. Each data point represents the mean $\pm \operatorname{SD}(n=3)$. a

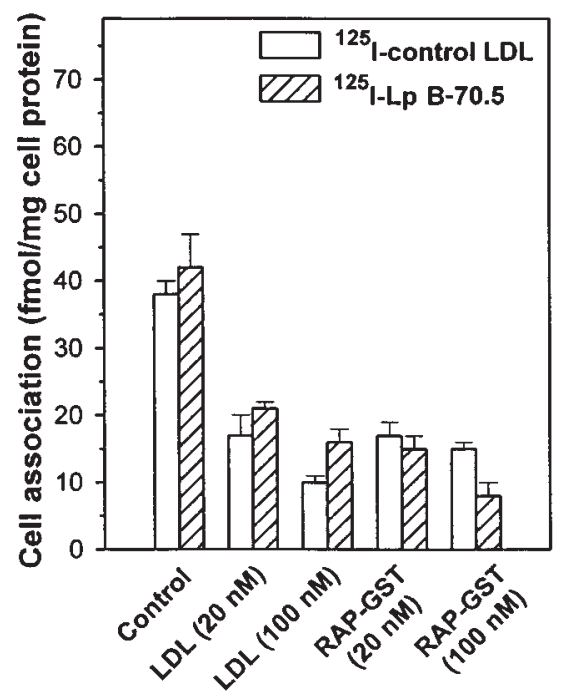

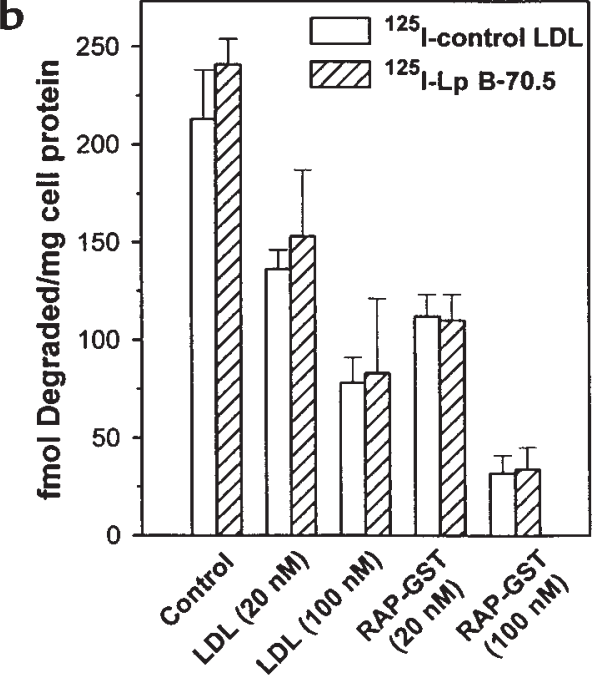

that only putative binding site B of apo B-100 shows a high degree of sequence identities to the LDL receptor-binding site on apo $\mathrm{E}(5,6,40)$. In addition, site $\mathrm{B}$ is highly conserved among many species (42). These 2 lines of evidence suggest that binding site B might be the more important putative binding site. Furthermore, during the preparation of our manuscript, Boren et al. (43) reported an elegant study in which they used human apo B-100 mutated at site B obtained from genetically engineered mice to demonstrate the preponderant importance of site $B$ in mediating the binding of LDL to the LDL receptor. Thus, our study, in conjunction with the previous studies, consistently indicates that putative binding site $\mathrm{B}$ is the functional recognition domain on apo B-100 for the $\mathrm{LDL}$ receptor. The precise role of site $\mathrm{B}$ in mediating the interactions between apo B-100 and the LDL receptor remains to be determined.

Another major finding of our study is that despite its inability to bind to the LDL receptor, apo B-70.5 avidly binds to megalin. First demonstrated by ligand blot analysis and solid phase-binding assay using purified megalin, subsequent experiments on F9 cells indicated that the binding of Lp B-70.5 to megalin in fact mediates the cellular uptake and catabolism of Lp B-70.5. Moreover, we have demonstrated that the $\mathrm{COOH}$-terminal fragment of the thrombin-cleaved product of apo B-100 that contains the $\mathrm{LDL}$ receptor-binding site $\mathrm{B}$, i.e., the $\mathrm{T} 2$ fragment (amino acids 3250-4536) (44), does not bind to megalin, whereas the fragment containing the remaining portion of apo B-100, i.e., the T1 fragment (amino acids 1-3249) (44), possesses the ability to bind to megalin. Thus, our study strongly suggests that the LDL receptor and megalin recognize different regions on apo B-100. This is not entirely unexpected. Although the LDL receptor and megalin belong to the same closely related protein family, the LDL receptor family $(18,19)$, they exhibit major differences in their ligand specificities. Unlike the LDL receptor, which binds only apo B-100 LDL and apo E with high affinity (1), megalin binds to a large number of unrelated ligands including RAP, plasminogen, type-I plasminogen activator inhibitor, aprotinin, and lipopro- tein lipase, as well as apo E and apo B $(17,19,29)$. Future studies to assess the interaction between the shorter forms of truncated apo B and megalin are likely to provide valuable information defining the apo B-binding site(s) recognized by this receptor.

Renal proximal tubule epithelium is the major site for megalin expression in vivo. Recent studies have demonstrated that this receptor plays a direct role in the receptor-mediated reabsorption of filtered proteins $(19,20$, 45) and calcium (46) by the proximal tubule cells. Although LDL particles are capable of binding to megalin, their ability to pass the glomerular filtration barrier is unclear. Our rabbit study demonstrated that the kidney contribution to the whole-body catabolism of normal LDL is about 10\% (Figure 4a). This is consistent with the results from our previous study (21). Moreover, autoradiographic analysis showed that most of the renal uptake of ${ }^{125}$ I-DLT-apo B-100 LDL occurred in proximal tubules, suggesting that megalin is also responsible for renal LDL uptake. A recent study (47) has also demonstrated megalin-mediated uptake of apo B-100 by the proximal tubule cells of the normal rat kidney. However, it remains to be examined whether the normal LDL particles taken up by the kidney are cleared as intact particles or after they are modified/remodeled.

In contrast to the normal LDL catabolism, our study demonstrated that the kidney plays an important role in catabolism of truncated apo B-containing lipoproteins through a megalin-mediated pathway. This conclusion is substantiated by our findings of the preponderance of Lp B-70.5 catabolism by the kidney in vivo, along with localization of the residualizing radiolabeled LP B-70.5 to proximal tubule cells and the ability of megalin to mediate cellular uptake of Lp B-70.5. We found very little uptake of Lp B-70.5 and apo B-100 LDL by rabbit renal glomeruli. It is not known whether megalin is expressed in rabbit renal glomeruli. However, human renal glomeruli do not express megalin (48), and thus it is unlikely for it to be involved in human glomerular uptake of apo B-containing particles. Currently, it is not understood how Lp B-70.5 particles are transported to the 
proximal tubules and why they are more accessible to the tubular megalin than the normal LDL particles. Both the size and the shape of a protein are important factors in determining its ability to pass the glomerular filtration barrier. Lp B-70.5 particles are smaller than those of the normal LDL. The difference in their particle size might be an important factor in allowing Lp B-70.5, but not normal LDL, to pass the glomerular membranes. Lipoprotein particles containing short truncation of apo $B$ are of even smaller sizes $(11,21)$, and, in fact, larger proportions of these abnormal lipoproteins are taken up by the kidney (21). Nonetheless, other changes in the physicochemical properties of apo $\mathrm{B}$ due to the $\mathrm{COOH}$-terminal truncation might also play a role in altering its ability to pass the glomerular membranes. An elucidation of the mechanism(s) involved in the glomerular filtration of the truncated apo B-containing lipoproteins will be important for understanding the pathophysiological role of megalin in lipoprotein metabolism.

\section{Acknowledgments}

The authors thank Bruce Patterson for his assistance in modeling the plasma kinetic data, Robin Fitzgerald for her technical assistance in the cell culture study, the members of the apo B70.5 kindred for their cooperation, and Sherry Banez-Muth for her assistance in obtaining the blood samples. We also thank Greg Grant and Mark Crankshaw of the Protein Sequencing Facility at the Washington University School of Medicine for their persistent efforts in obtaining partial amino acid sequence of the purified megalin. This work was supported by National Institutes of Health grants HL RO1 42460, RO1 59515, and RO1 07456-16, and General Clinical Research Center grant USPHS MO 1 RR00036.

1. Brown, M.S., and Goldstein, J.L. 1986. A receptor-mediated pathway for cholesterol homeostasis. Science. 232:34-47.

2. Mahley, R.W., Innerarity, T.L., Rall, S.C., Jr., and Weisgraber, K.H. 1984. Plasma lipoproteins: apolipoprotein structure and function. J. Lipid Res. 25:1450-1461.

3. Hobbs, H.H., Brown, M.S., and Goldstein, J.L. 1992. Molecular genetics of the LDL receptor gene in familial hypercholesterolemia. Hum. Mutat. 1:445-466.

4. Chan, L. 1992. Apolipoprotein B, the major protein component of triglyceride-rich and low density lipoproteins. J. Biol. Chem. 267:25621-25624.

5. Knott, T.J., et al. 1986. Complete protein sequence and identification of structural domain of human apolipoprotein B. Nature. 323:734-738.

6. Yang, C.Y., et al. 1986. Sequence, structure, receptor-binding domains and internal repeats of human apolipoprotein B-100. Nature. 323:738-742.

7. Nelson, C.A., Tash, M.A., Tikkanen, M., Dargar, R., and Schonfeld, G. 1984 Evolution of low density lipoprotein structure probed with monoclonal antibodies. J. Lipid Res. 25:821-830.

8. Young, S.G., Witztum, J.L., Casal, D.C., Linda, K.C., and Bernstein, S. 1986. Conservation of the low density lipoprotein receptor-binding domain of apoprotein B: demonstration by a new monoclonal antibody, MB47. Arteriosclerosis. 6:178-188.

9. Milne, R., et al. 1989. The use of monoclonal antibodies to localize the low density lipoprotein receptor-binding domain of apolipoprotein B. J. Biol. Chem. 264:19754-19760.

10. Krul, E.S., et al. 1988. Regional specificities of monoclonal anti-human apolipoprotein B antibodies. J. Lipid Res. 29:937-947.

11. Schonfeld, G. 1995. The hypobetalipoproteinemias. Annu. Rev. Nutr. 15:23-34.

12. Krul, E.S., Parhofer, K.G., Barrett, P.H.R., Wagner, R.D., and Schonfeld, G. 1992. ApoB-75, a truncation of apolipoprotein B associated with familial hypobetalipoproteinemia: genetic and kinetic studies. J. Lipid Res. 33:1037-1050.

13. Young, S.G., et al. 1987. Lipoprotein B37, a naturally occurring lipoprotein containing the amino-terminal portion of apolipoprotein B-100, does not bind to the apolipoprotein B/E (low density lipoprotein) receptor. J. Biol. Chem. 262:16604-16611.

14. Welty, F.K., Seman, L., and Yen, F.T. 1995. Purification of the apolipopro- tein B-67-containing low density lipoprotein particle and its affinity for the low density lipoprotein receptor. J. Lipid Res. 36:2622-2629.

15. Groenewegen, W.A., Krul, E.S., Averna, M.R., Pulai, J., and Schonfeld, G. 1994. Dysbetalipoproteinemia in a kindred with hypobetalipoproteinemia due to mutations in the genes for apoB (apoB-70.5) and apoE (apoE2). Arterioscler. Thromb. 14:1695-1704.

16. Weisgraber, K.H., Innerarity, T.L., and Mahley, R.W. 1982. Abnormal lipoprotein receptor binding activity of human $\mathrm{E}$ apoprotein due to cysteine-arginine interchange at a single site. J. Biol. Chem. 257:2518-2521.

17. Stefansson, S., Chappell, D.A., Argraves, K.M., Strickland, D.K., and Argraves, W.S. 1995. Glycoprotein 330/low density lipoprotein receptorrelated protein-2 mediates endocytosis of low density lipoproteins via interaction with apolipoprotein B-100. J. Biol. Chem. 270:19417-19421.

18. Saito, A., Pietromonaco, S., Loo, A., and Farquhar, M.G. 1994. Complete cloning and sequencing of rat megalin, a distinctive member of the low density lipoprotein receptor gene family. Proc. Natl. Acad. Sci. USA. 91:9725-9729.

19. Kounnas, M.Z., et al. 1994. An overview of the structure and function of glycoprotein 330 , a receptor related to the $\alpha_{2}$-macroglobulin receptor. Ann. NY Acad. Sci. 737:114-123.

20. Farquhar, M.G., Saito, A., Kerjaschki, D., and Orlando, R. 1995. The Heymann nephritis antigenic complexed: megalin (gp330) and RAP. J. Am. Soc. Nephrol. 6:35-47.

21. Zhu, X., Noto, D., Seip, R., Shaish, A., and Schonfeld, G. 1997. Organ loci of catabolism of short truncations of apoB. Arterioscler. Thromb. Vasc. Biol. 17:1032-1038

22. Herz, J., Goldstein, J.L., Strickland, D.K., Ho, Y.K., and Brown, M.S. 1991. 39-kDa protein modulates binding of ligands to low density lipoprotein receptor-related protein $/ \alpha_{2}$-macroglobulin receptor. J. Biol. Chem. 266:21232-21238.

23. Havel, R.J., Eder, H.A., and Bragdon, J.H. 1955. The distribution and chemical composition of ultracentrifugally separated lipoproteins in human serum. J. Clin. Invest. 34:1345-1353.

24. Bilheimer, D.W., Eisenberg, S., and Levy, R.I. 1972. The metabolism of very low density lipoprotein proteins. I. Preliminary in vitro and in vivo observations. Biochim. Biophys. Acta. 260:212-218.

25. Strobel, J.L., Baynes, J.W., and Thorpe, S.R. 1985. ${ }^{125}$ I-glycoconjugate labels for identifying sites of protein catabolism in vivo: effect of structure and chemistry of coupling of protein on label entrapment in cells after protein degradation. Arch. Biochem. Biophys. 240:635-645.

26. Daugherty, A., Thorpe, S.P., Lange, L.G., Sobel, B.E., and Schonfeld, G. 1985 . Loci of catabolism of $\beta$-very low density lipoprotein in vivo delineated with a residualizing label, ${ }^{125}$ I-dilactitol tyramine. J. Biol. Chem. 260:14564-14570

27. Berman, M. 1978. SAAM manual. Department of Health, Education, and Welfare. Washington, DC. NIH publication no. 78-180:1-196.

28. Latimer, H.B., and Sawin, P.B. 1957. Morphogenetic studies of the rabbit. Anat. Rec. 129:457-471.

29. Moestrup, S.K., et al. 1993. Epithelial glycoprotein-330 mediates endocytosis of plasminogen activator-plasminogen activator inhibitor type-1 complexes. J. Biol. Chem. 268:16564-16570.

30. Schneider, W.J., Beisiegel, U., Goldstein, J.L., and Brown, M.S. 1982. Purification of the low density lipoprotein receptor, an acidic glycoprotein of 164,000 molecular weight. J. Biol. Chem. 257:2664-2673.

31. Davis, C.G., et al. 1986. Deletion of clustered $O$-linked carbohydrates does not impair function of low density lipoprotein receptor in transfected fibroblasts. J. Biol. Chem. 261:2828-2838.

32. Drevon, C.A., Attie, A.D., Pangburn, S.H., and Steinberg, D. 1981. Metabolism of homologous lipoproteins by cultured rat and human skin fibroblasts. J. Lipid Res. 22:37-46.

33. Goldstein, J.L., Basu, S.K., and Brown, M.S. 1983. Receptor-mediated endocytosis of low density lipoprotein in cultured cells. Methods Enzymol. 98:241-260.

34. Czekay, R.-P., Orlando, R.A., Woodward, L., Adamson, E.D., and Farquhar, M.G. 1995. The expression of megalin (gp330) and LRP diverges during F9 cell differentiation. J. Cell Sci. 108:1433-1441.

35. Schegler, J.S., Heppelmann, B., Mildenberger, S., and Silbernagl, S. 1991. Receptor-mediated endocytosis of albumin in cultured opossum kidney cells: a model for proximal tubular protein reabsorption. Pflugers Arch. 418:383-392.

36. Thomas, M.E., Morrison, A.R., and Schreiner, G.F. 1995. Metabolic effects of fatty acids-bearing albumin on a proximal tubule cell line. Am. J. Physiol. 268:F1177-F1184.

37. Marwell, M.A., Haas, S.M., Bieber, L.L., and Tolbert, N.E. 1978. A modification of the Lowry procedure to simplify protein determination in membrane and lipoprotein samples. Anal. Biochem. 87:206-210.

38. Hjalm, G., et al. 1996. Cloning and sequencing of human gp330, a Ca (2+)binding receptor with potential intracellular signaling properties. Eur.J. Biochem. 239:132-137.

39. Gwynne, J.T., and Strauss, J.F., III. 1982. The role of lipoproteins in steroidogenesis and cholesterol metabolism in steroidogenic glands. Endocr. Rev. 3:299-329. 
40. Mahley, R.W. 1988. Apolipoprotein E: cholesterol transport protein with expanding role in cell biology. Science. 240:622-630.

41. Wilson, C., Wardell, M.R., Weisgraber, K.H., Mahley, R.W., and Agard, D.A. 1991. Three-dimensional structure of the LDL receptor-binding domain of human apolipoprotein E. Science. 252:1817-1822.

42. Law, A., and Scott, J. 1990. A cross-species comparison of the apolipoprotein B domain that binds to the LDL receptor. J. Lipid Res. 31:1109-1120.

43. Boren, J., et al. 1998. Identification of the low density lipoprotein receptorbinding site in apoprotein B-100 and the modulation of its binding activity by the carboxyl terminus in familial defective apo-B-100. J. Clin. Invest. 101:1084-1093.

44. Cardin, A.D., et al. 1984. Degradation of apolipoprotein B-100 of human plasma low density lipoproteins by tissue and plasma kallikreins. J. Biol.
Chem. 259:8522-8528.

45. Cui, S., Verroust, P.J., Moestrup, S.K., and Christensen, E.I. 1996. Megalin mediates uptake of albumin in renal proximal tubule. Am. J. Physiol. 271:F900-F907.

46. Christensen, E.I., Gliemann, J., and Meostrup, S.K. 1992. Renal tubule $\mathrm{gp} 330$ is a calcium binding receptor for endocytic uptake of protein. J. Histochem. Cytochem. 40:1481-1490.

47. Kerjaschki, D., et al. 1997. Pathogenic antibodies inhibit the binding of apolipoproteins to megalin in passive Heymann nephritis. J. Clin. Invest. 100:2303-2309.

48. Kerjaschki, D., et al. 1987. Identification of a $400-\mathrm{kD}$ protein in the brush borders of human kidney tubules that is similar to gp330, the nephritogenic antigen of rat Heymann nephritis. Am. J. Pathol. 129:183-191. 